\title{
Suspected Pulmonary Embolism during Hickman Catheterization in a Child: What Else Should Be Considered besides Pulmonary Embolism?
}

\author{
Haemi Lee, M.D., Ph.D. ${ }^{1}$, Jonghyun Baek, M.D. ${ }^{2}$, Sangyoung Park, M.D. ${ }^{1}$, and Daelim Jee, M.D., Ph.D. ${ }^{1}$ \\ ${ }^{1}$ Department of Anesthesiology and Pain Medicine, ${ }^{2}$ Department of Thoracic Surgery, College of Medicine, Yeungnam University, Daegu, Korea
}

\begin{abstract}
A 16-month-old girl with acute lymphoblastic leukemia expired during Hickman catheter insertion. She had undergone chemoport insertion of the left subclavian vein six months earlier and received five cycles of chemotherapy. Due to malfunction of the chemoport and the consideration of hematopoietic stem cell transplantation, insertion of a Hickmann catheter on the right side and removal of the malfunctioning chemoport were planned under general anesthesia. The surgery was uneventful during catheter insertion, but the patient experienced the sudden onset of pulseless electrical activity just after saline was flushed through the newly inserted catheter. Cardiopulmonary resuscitation was commenced aggressively, but the patient was refractory. Migration of a thrombus generated by the previous central catheter to the pulmonary circulation was suspected, resulting in a pulmonary embolism.
\end{abstract}

Key Words: cardiopulmonary resuscitation; central venous catheters; pediatrics; pulmonary embolism.

Pediatric pulmonary embolism (PE) is not as common as in adults. The annual incidence of childhood PE has been reported as 0.86/10,000 hospital admissions in Canada and 0.14-0.9/100,000 children in the Netherlands.[1,2] However, the evidence suggests that the incidence is under-recognized because of a low index of suspicion and the masking of symptoms by underlying disease in pediatric settings. Therefore, the condition is mainly diagnosed at autopsy and the mortality rate was reported to be around 10\%.[1] PE originates most commonly from deep venous thrombosis (DVT) in conditions of venous stasis, endothelial damage, and hypercoagulable states. These situations are frequently induced by cancer, because chemotherapeutic agents release hormones causing hypercoagulable states, patients often experience reduced mobility and the frequent presence of a central venous catheter (CVC), or there is possible venous obstruction from the tumor itself. The presence of CVCs is the single most important risk factor for DVT in children; 94\% of neonates and 37\% of children 1 month to 18 years of age who have DVT has been reported to have CVCs.[2] The American College of Chest Physicians guidelines reported that at least $85 \%$ of DVTs are related to CVCs and nearly all DVT-related deaths are associated with CVCs.[3,4] Herein, we report a case in a cancer patient of suspected PE due to migration of a thrombus from a previously inserted CVC.

Received on December 21, 2015 Revised on February 2, 2016 Accepted on February 14, 2016

Correspondence to: Haemi Lee, Department of Anesthesiology and Pain Medicine, College of Medicine, Yeungnam University, 170 Hyeonchung-ro, Nam-gu, Daegu 42415, Korea

Tel: +82-53-620-3361, Fax: +82-53-525-5276

E-mail: hmlee@yu.ac.kr

*No potential conflict of interest relevant to this article was reported.

\section{Case Report}

A 16-month-old girl with acute lymphoblastic leukemia (8 $\mathrm{kg} / 73 \mathrm{~cm}$ ) was scheduled to undergo insertion of a Hickman catheter for chemotherapy. She had received a chemoport (Celsite $^{\circledR}$ Babyport $^{\circledR} 4.5$ Fr, B. Braun Medical, Boulogne Cedex, France) insertion six months earlier on the left subcla-

(cc) This is an Open Access article distributed under the terms of the Creative Commons Attribution Non-Commercial License (http://creativecommons.org/ licenses/by-nc/3.0/) which permits unrestricted non-commercial use, distribution, and reproduction in any medium, provided the original work is properly cited. Copyright (c) 2016 The Korean Society of Critical Care Medicine 
Table 1. Patient's treatment course

\begin{tabular}{|c|c|c|c|c|c|c|}
\hline Chemotherapy & $1^{\text {st }}$ & $2^{\text {nd }}$ & $3^{\text {rd }}$ & $4^{\text {th }}$ & $5^{\text {th }}$ & $6^{\text {th }}$ \\
\hline $\mathrm{Hb}(\mathrm{g} / \mathrm{dL})$ & $4.7-11.6$ & $7.9-12.8$ & 7.4-10.8 DIC & $6.3-12.2$ & $7.1-12.2$ & $8.3-11.7$ \\
\hline 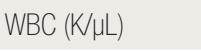 & $0.36-49.86$ & $0.2-9.04$ & $1.83-5.2$ & $0.92-7.71$ & $0.57-7.56$ & $2.37-4.3$ \\
\hline PLT (K/LL) & $14-522$ & $9-504$ & $96-284$ & $50-373$ & $5-650$ & $75-325$ \\
\hline PT (sec) & $10.5-12.8$ & $10.0-15.7$ & 13.1 & $10.7-12.4$ & $10.5-25.2$ & $13.6-14.1$ \\
\hline PTT (sec) & $18.1-37.5$ & $17.8-44.6$ & 166.5 & 38.0-ncd & 26.3-ncd & 35.4-ncd \\
\hline D dimer ( $\mu \mathrm{g} / \mathrm{ml})$ & 4.52 & $0.38-3.33$ & 0.32 & $0.24-1.16$ & $0.16-8.35$ & $0.22-0.28$ \\
\hline Fever $\left({ }^{\circ} \mathrm{C}\right)$ & & 40 & & 38.7 & 39 & 39.1 \\
\hline $\begin{array}{l}\text { Performance state } \\
\text { (ECOG) }\end{array}$ & 1 & 3 & 2 & 2 & 3 & 2 \\
\hline Events & Chemoport insertion & $\begin{array}{l}\text { Pneumonia } \\
\mathrm{R} / 0 \text { sepsis }\end{array}$ & & Chemoport fixation & $\begin{array}{l}\text { Sepsis, DIC, UTI, } \\
\text { hepatitis }\end{array}$ & $\begin{array}{l}\text { Hickmann catheter } \\
\text { insertion }\end{array}$ \\
\hline
\end{tabular}

Hb: hemoglobin, WBC: white blood cell, PLT: platelet, PT: prothrombin time, PT: partial thromboplastin time, ECOG: Eastern Cooperative Oncology Group, ncd: not clot detect, DIC: disseminated intravascular coagulation, UTI: urinary tract infection.

vian vein and had a fixation two months earlier because of a rotated chemoport. Two weeks after successful treatment via indwelling chemoport on $5^{\text {th }}$ chemotherapy, the patient was admitted for the next chemotherapy and noticed that the chemoport was not functioning well. As hematopoietic stem cell transplantation was considered, removal of chemoport and insertion of Hickmann catheter were planned. She experienced no specific complications during the previous operations and recovered from the anesthesia without any problems. Her echocardiography taken after the chemoport fixation was non-specific either. She received chemotherapy with cytarabine, methotrexate, endoxan and vincristine, andheparin and urokinase were used for anticoagulation (Table $1)$.

At the time of the surgery, she did not have any premedication and she was monitored with non-invasive blood pressure, electrocardiography (ECG), oxygen saturation $\left(\mathrm{SpO}_{2}\right)$, and end-tidal $\mathrm{CO}_{2}\left(\mathrm{EtCO}_{2}\right)$. Thiopental sodium 40 $\mathrm{mg}$ and rocuroniumbromide $5 \mathrm{mg}$ were used for anesthetic induction. Intubation was commenced with an internal diameter 4.0 endotracheal tube and sevoflurane was used for anesthetic maintenance. During the insertion of the catheter, the patient had blood pressure (BP) between 90-100/45-50 $\mathrm{mmHg}$, heart rate (HR) 120-130 beats/min, $\mathrm{SpO}_{2}$ 99-100\%, and $\mathrm{EtCO}_{2}$ 33-35 mmHg. Full length of the Hickman catheter (Hickman 7 Fr. Dual Lumen CV Catheter ${ }^{\circledR}$, BARD, Murray Hill, New Jersey, USA) was filled with heparin mixed solution (heparin 2,000 IU in $100 \mathrm{~mL}$ normal saline) and fixed in the patient's right subclavian vein. Catheter function

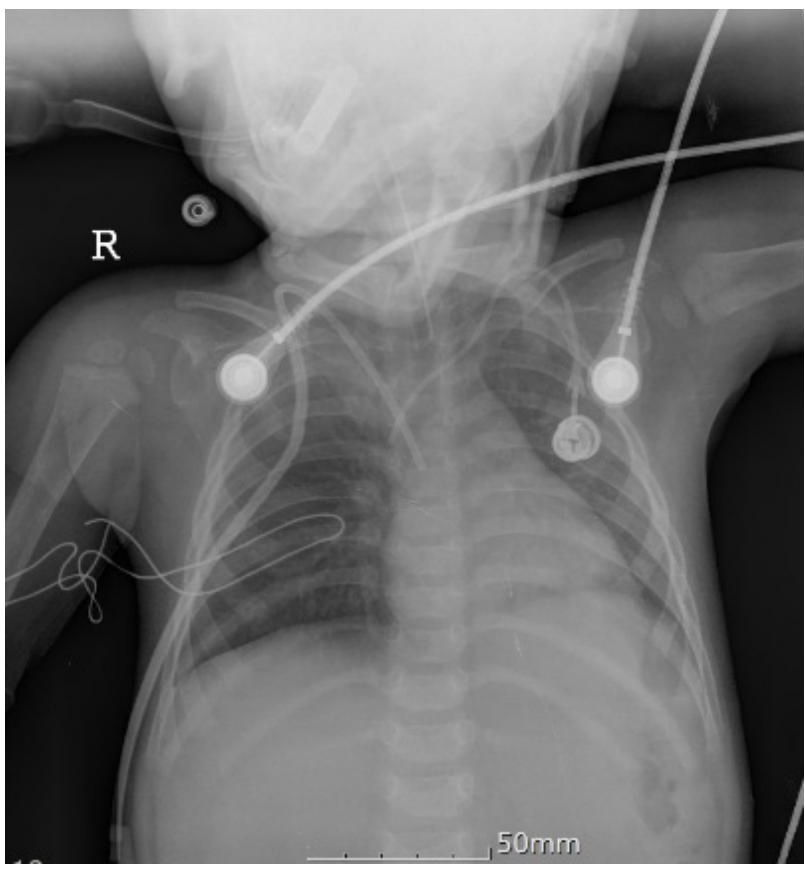

Fig.1. Chest radiograph during cardiopulmonary resuscitation shows increased haziness in the left lower lung field and suspicious right upper lung field consolidation. Both the previously inserted left-side catheter and the newly inserted right-side catheter are shown. The depth of the endotracheal tube and catheter seem to be adequate, and other possibilities of cardiac arrest such as tension pneumothorax were excluded.

was confirmed by free flow of regurgitation and then $10 \mathrm{~mL}$ of heparin mixed warm saline was slowly injected through the catheter. At that time, the patient's HR increased from 120 to 140 beats/min for a few seconds and then decreased precipitously to 50 beats/min. Simultaneously, her $\mathrm{EtCO}_{2}$ 
decreased to less than $20 \mathrm{mmHg}$, and subsequently her BP and $\mathrm{SpO}_{2}$ could not be measured. The patient's ECG showed pulseless electrical activity (PEA) of 30-40 bpm. We immediately stopped the administration of anesthesia and started chest compressions. Epinephrine 100 mcg was injected a few times under manual bagging with $100 \%$ oxygen. Airway resistance could not be detected by manual bagging and tidal volumes were adequate. Endotracheal suction was attempted but nothing could be sucked out and pulmonary sounds were heard bilaterally on chest auscultation. The arterial blood gas analysis just after initiation of cardiopulmonary resuscitation (CPR) showed $\mathrm{pH} 7.18, \mathrm{PaCO}_{2} 106$ $\mathrm{mmHg}, \mathrm{PaO}_{2} 15 \mathrm{mmHg}$, and after 30 minutes, $\mathrm{pH}<6.80$, $\mathrm{PaCO}_{2}>115 \mathrm{mmHg}, \mathrm{PaO}_{2} 14 \mathrm{mmHg}$ under $\mathrm{FiO}_{2}$ 1.0. Serum $\mathrm{Na}$ was $136 \mathrm{mmol} / \mathrm{L}, \mathrm{K} 4.0 \mathrm{mmol} / \mathrm{L}$, Ca $1.18 \mathrm{mmol} /$ L, Het $27 \%$ and blood sugar $221 \mathrm{mg} / \mathrm{dL}$. Portable chest Xray showed no specific findings (Fig.1). Despite aggressive CPR, the patient did not recover from cardiac arrest. The parents refused autopsy.

\section{Discussion}

This case was considered to be a pulmonary thromboembolism (PTE) due to migration of a venous thrombus arising from the previous central catheter. Although many diagnostic tools failed to be applied in this case because of the sudden onset compromise, the intraoperative situation, monitoring, and laboratory findings may reflect this case as a PTE. The sudden onset of hypoxemia and bradycardia right after the saline flush at the end of the procedure might reflect the dislodging of thrombotic material adherent to the vessel wall or the previous catheter and its migration to the pulmonary arteries. The malfunctioning of a long-standing previous central catheter may reflect the possibility of thrombosis, as well. The sudden onset of PEA despite no previous cardiac or metabolic problems, a very low $\mathrm{PaO}_{2}$ and a wide $\mathrm{EtCO}_{2}-\mathrm{PaCO}_{2}$ gap despite $100 \%$ oxygen delivery by manual bagging at the time of attack, and are fractory state despite aggressive CPR are sufficient to strongly suggest PE. As the diameter of pulmonary vessels is small in children, even a small amount of thrombus may occlude major or several peripheral pulmonary arteries with a severe hemodynamic event, thus resulting in a life-threatening complication.
Actually diagnosing PE is not easy especially in anesthetized, mechanically ventilated patients. In most cases, dyspnea and tachycardia accompany PE, but these could be masked or misread during general anesthesia. In this case, the sudden bradycardia just after the saline injection was first thought to be a reflex phenomenon, but it was not resolved by epinephrine injection. Elevated HR was noticed for a very short period, but it was in an acceptable range and this could also appear due to decreased anesthetic delivery at the end of surgery. Derish et al.[5] reported that among five patients out of 1,033 patients in the pediatric intensive care unit (PICU) who died of PE during an 18-monthperiod, only one patient was diagnosed ante mortem, and the rest were not diagnosed until autopsy. All of patients had CVCs and the thrombus was found in a corresponding insertion site.

CVCs are increasingly used in clinical practice. In a remarkable proportion of patients, $\mathrm{PE}$ is the first clinical manifestation of the silent nature of CVC-associated thrombi, and a history of CVC malfunction is not uncommon in patients with CVC-related DVT.[6] Prospective studies reveal that asymptomatic central venous line-related thrombosis occurs more frequently in children and the presence of CVCs led to a nine-fold increased risk factor of venous thromboembolism (VTE) in the PICU.[1,7-10] That isbecause flow stasis is more prominentin children because they have a higher CVC/vein ratio.[11] Left-side insertionthrough thesubclavian vein is associated with an increased risk for VTE because a longer horizontal course leads to a sharper angle to the SVC, thus increasing the potential for endothelial damage.[12] A large case-control study developing a new risk score for hospital-associated VTE in noncritically ill children revealed a CVC, infection, and length of stay more than four days as significant risk factors for VTE, and of the risk factor of CVC, $94 \%$ of CVCs were located at the same location as the clot.[13]

In acute PE, markedly reduced values for $\mathrm{EtCO}_{2}$ and as increased difference between arterial and end-tidal $\mathrm{CO}_{2}$ measures would be observed.[14] In pulmonary arterial obstruction, the pulmonary dead space is increased and pulmonary capacity for the elimination of $\mathrm{CO}_{2}$ is reduced.[15] In severe pulmonary arterial obstruction, cardiac output and pulmonary arterial perfusion are reduced; therefore, the pulmonary arterial supply of $\mathrm{CO}_{2}$ is low and the alveolar $\mathrm{CO}_{2}$ diffusion 
Table 2. Difference between $\mathrm{O}_{2}$ and $\mathrm{CO}_{2}$ during $\mathrm{CPR}$

\begin{tabular}{lcccc}
\hline & Initiation of CPR & After 5 min & After 20 min & After 30 min \\
\hline $\mathrm{EtCO}_{2}(\mathrm{mmHg})$ & 19 & Irregular & Irregular & Irregular \\
$\mathrm{PaCO}_{2}(\mathrm{mmHg})$ & 106 & 70 & $>115$ & $>115$ \\
$\mathrm{PAO}_{2}(\mathrm{mmHg})$ & 580.5 & 625.5 & 569.3 & 569.3 \\
$\mathrm{PaO}_{2}(\mathrm{mmHg})$ & 15 & 17 & 10 & 14 \\
$\mathrm{D}(\mathrm{A}-\mathrm{a}) \mathrm{O}_{2}(\mathrm{mmHg})$ & 565.5 & 608.5 & 559.3 & 555.3 \\
\hline
\end{tabular}

D (A-a) $\mathrm{O}_{2}$ was calculated as $\left(\mathrm{FiO}_{2}\left[\mathrm{P}_{\text {atm }}-\mathrm{P}_{\mathrm{H} 2 \mathrm{O}}\right]-\mathrm{PaCO}_{2} / 0.8\right)-\mathrm{PaO}_{2} \cdot \mathrm{P}_{\text {atm: }}: 760 \mathrm{mmHg}, \mathrm{P}_{\mathrm{H} 2 \mathrm{O}}: 47 \mathrm{mmHg}$. PaCO $\mathrm{P}_{2}>115$ was calculated as 115.

CPR: cardiopulmonary resuscitation, $\mathrm{EtCO}_{2}$ : end-tidal $\mathrm{CO}_{2}, \mathrm{PaCO}_{2}$ : arterial $\mathrm{CO}_{2}$ partial pressure, $\mathrm{PaO}_{2}$ : arterial $\mathrm{O}_{2}$ partial pressure.

is reduced.[16] However, this phenomenon is not limited to PE only, and left-sided heart failure rather than PE itself may also cause the specific $\mathrm{PaCO}_{2}$-EtCO 2 trend. However, in this case, the difference between arterial and end-tidal $\mathrm{CO}_{2}$ and the difference between arterial and alveolar $\mathrm{O}_{2}$ was too extreme even during the early period of CPR with adequate chest compressions and ventilations (Table 2). The occurrence of an unexplained shock right after the injection of the irrigating fluid may reflect the possibility of PE. This difference cannot be explained except for the abrupt cessation of pulmonary circulation.

The administration of thrombolytic therapy during CPR in adult patients had been reported to reduce the mortality, although it has classically been contraindicated.[17] It is a high risk procedure that can produce serious complications such as fatal hemorrhage. Pavlovic et al.[18] reported a case of massive PE in an adult patient, who was successfully treated with extracorporeal membrane oxygenation (ECMO). They recommended considering ECMO as a firstline therapy although current guidelines do not consider it a first-line therapy. However, undetected PE is unfortunately too common in pediatric patients and most of them were proved by autopsy, so making the decision to administer thrombolyticsor ECMO in these situations is challenging.

In conclusion, this case was considered to be a PTE due to migration of a venous thrombus generated by a previous chemoport. The choice of treatment depends on the clinical presentation, but diagnosis is often subtle or masked by the underlying clinical condition or general anesthesia during surgery. Therefore, physicians should be alert to the possibility of PE at risk, especially those with prolonged indwelling catheters. It is recommended to screen the venous system before removing or reinserting a central line although most catheter-related thrombi are asymptomatic. A combination of duplex ultrasound (US) and venography is recommended for the screening. US can be used to confirm the DVT, and patients with positive US should be treated with anticoagulant therapy. Patients with negative US may undergo venography.[6] Although there is little evidence for efficacy or safety of systemic anticoagulation to prevent CVC-related VTE in children, it is essential to precede anticoagulation therapy at least three to five days. CVC should be removed as soon as possible when it is no longer required or is not functioning.

\section{References}

1) Biss TT, Brandão LR, Kahr WH, Chan AK, Williams S: Clinical features and outcome of pulmonary embolism in children. Br J Haematol 2008; 142: 808-18.

2) van Ommen $\mathrm{CH}$, Heijboer H, Büller HR, Hirasing RA, Heijmans HS, Peters M: Venous thromboembolism in childhood: a prospective two-year registry in The Netherlands. J Pediatr 2001; 139: 676-81.

3) Monagle P, Chan AK, Goldenberg NA, Ichord RN, Journeycake JM, Nowak-Göttl U, et al: Antithrombotic therapy in neonates and children: Antithrombotic Therapy and Prevention of Thrombosis, 9th ed: American College of Chest Physicians Evidence-Based Clinical Practice Guidelines. Chest 2012; 141(2 Suppl): e737S$801 \mathrm{~S}$.

4) Vidal E, Sharathkumar A, Glover J, Faustino EV: Central venous catheter-related thrombosis and thromboprophylaxis in children: a systematic review and metaanalysis. J Thromb Haemost 2014; 12: 1096-109.

5) Derish MT, Smith DW, Frankel LR: Venous catheter thrombus formation and pulmonary embolism in chil- 
dren. Pediatr Pulmonol 1995; 20: 349-54.

6) Verso M, Agnelli G: Venous thromboembolism associated with long-term use of central venous catheters in cancer patients. J Clin Oncol 2003; 21: 3665-75.

7) Higgerson RA, Lawson KA, Christie LM, Brown AM, McArthur JA, Totapally BR, et al: Incidence and risk factors associated with venous thrombotic events in pediatric intensive care unit patients. Pediatr Crit Care Med 2011; 12: 628-34.

8) Krafte-Jacobs B, Sivit CJ, Mejia R, Pollack MM: Catheter-related thrombosis in critically ill children: comparison of catheters with and without heparin bonding. J Pediatr 1995; 126: 50-4 .

9) Male C, Chait P, Ginsberg JS, Hanna K, Andrew M, Halton J, et al: Comparison of venography and ultrasound for the diagnosis of asymptomatic deep vein thrombosis in the upper body in children: results of the PARKAA study. Prophylactic antithrombin replacement in kids with aLL treated with asparaginase. Thromb Haemost 2002; 87: 593-8.

10) Massicotte MP, Dix D, Monagle P, Adams M, Andrew M: Central venous catheter related thrombosis in children: analysis of the Canadian Registry of Venous Thromboembolic Complications. J Pediatr 1998; 133: 770-6.

11) Nifong TP, McDevitt TJ: The effect of catheter to vein ratio on blood flow rates in a simulated model of peripherally inserted central venous catheters. Chest 2011; 140: 48-53.
12) Male C, Chait P, Andrew M, Hanna K, Julian J, Mitchell L; PARKAA Investigators: Central venous linerelated thrombosis in children: association with central venous line location and insertion technique. Blood 2003; 101: 4273-8.

13) Atchison CM, Arlikar S, Amankwah E, Ayala I, Barrett L, Branchford BR, et al: Development of a new risk score for hospital-associated venous thromboembolism in noncritically ill children: findings from a large single-institutional case-control study. J Pediatr 2014; 165 : 793-8.

14) Weg JG: A new niche for end-tidal $\mathrm{CO} 2$ in pulmonary embolism. Crit Care Med 2000; 28: 3752-4.

15) Stockwell MA, Bruce W, Soni N: The influence of CO2 production and physiological deadspace on end-tidal $\mathrm{CO} 2$ during controlled ventilation: a study using a mechanical model. Anaesth Intensive Care 1989; 17: 482-6.

16) Wiegand UK, Kurowski V, Giannitsis E, Katus HA, Djonlagic H: Effectiveness of end-tidal carbon dioxide tension for monitoring thrombolytic therapy in acute pulmonary embolism. Crit Care Med 2000; 28: 3588-92.

17) Bailén MR, Cuadra JAR, Aguayo De Hoyos E: Thrombolysis during cardiopulmonary resuscitation in fulminant pulmonary embolism: a review. Crit Care Med 2001; 29: 2211-9.

18) Pavlovic G, Banfi C, Tassaux D, Peter RE, Licker MJ, Bendjelid K, et al: Peri-operative massive pulmonary embolism management: is veno-arterial ECMO a therapeutic option? Acta Anaesthesiol Scand 2014; 58: 1280-6. 